\title{
Digitization in the Oil and Gas Industry: Challenges and Opportunities for Supply Chain Partners
}

\author{
Arda Gezdur and Jyotirmoyee Bhattacharjya \\ ${ }^{1}$ Institute of Transportation and Logistics Studies, \\ The University of Sydney, NSW 2006, Australia \\ \{arda.gezdur, jyotirmoyee.bhattacharjya\}@sydney.edu.au
}

\begin{abstract}
Declining oil prices have made it necessary for oil and gas companies to scrutinize their operations and associated costs. The increase in data richness from the digitization of supply chain processes could help these companies manage risks, and increase collaboration and profitability. This paper explores the challenges and opportunities for oil and gas industry in this context.
\end{abstract}

Keywords: Supply chain digitization, supply visibility, supply chain integration, oil and gas

\section{Introduction}

Oil and gas are key sources of energy that provide a foundation for global economic growth. Firms in the oil and gas industry require complex machinery and a large amount of capital investment. Thus, there are huge barriers for other companies wishing to enter the industry. Over the years, the industry has experienced high profitability so digitization has largely been a "nice-to-have". However, the recent fall in oil prices due to increasing supply alternatives and slower growth in demand provides motivation for companies to focus on leaner operations and cost reduction.

Oil and gas supply chains are composed of segmented and discrete data hubs. There is little transparency across entities in the supply chain. Even within companies, data is stored and managed separately by different divisions and there is discontinuity in process flows [15]. Decisions are taken based on disparate spreadsheets without consideration of the full picture. Appropriate digitization strategies could help with supply chain integration and information sharing between suppliers, transporters, storage facilities and customers.

\section{Supply Chain Digitization in the Oil and Gas Industry}

The need for supply chain digitization and the potential benefits have received growing attention in the literature ([12], [14], [17], [18], and [19]). Current trends in the digitization of supply chains include 3D printing, Uberization, internet of 
technologies, cloud computing, advanced robotics and drones [7]. The oil and gas industry can be regarded as a 'latecomer industry' [1] in this context. The literature on digitization and supply chain visibility for the oil and gas sector is scarce and diverse. A clear pathway is needed for evolution towards a highly efficient digital ecosystem in the oil and gas industry. Studies on the digitization of supply chains focus on integrating operational technology systems with information technology systems using big data [5]. Use of big data and integration of operational and information technologies are crucial for digitization of supply chains [6].

Digital transformation projects can take considerable effort and time. For instance, a supervisory control and data acquisition (SCADA) project undertaken by Encana in the United States was undertaken over a 12-year period [1]. As an upstream company, Encana senior managers had sought different alternatives for responding to price volatility and reducing production costs by seeking unconventional sources of natural gas. This project helped Encana improve supply chain visibility by embedding digital technologies to integrate its data and establish new information systems policies.

Although the upstream oil companies are not new to big data analytics, most of them are in preliminary stages of implementing relevant technologies [8]. Companies are benefitting from the sensors embedded in their drilling operations and are working on integrating this data with their supply chain information systems. Oil and gas companies need to carry out a gap analysis before investing on digitization. Furthermore, these companies need to create new strategies to utilize the big data for their decision making processes.

The extent of digitization within individual companies influences the digitization within the overall supply chain. Furthermore, supply chain collaboration between the companies also influences and improves companies' performances [21]. Supply chain collaboration is also directly linked with interorganizational dependencies, as past collaboration activities can be used as a basis for defining the dependencies. Among the different types of interorganizational dependencies, sequential and reciprocal dependencies matter for oil and gas companies. If companies in a suppliercustomer relation agree to use a specific resource and if the product of one is a raw material for the other company, the arrangement is described as sequential dependency. In such a dependency, the technologies of the supplier and customer companies need to be linked. In reciprocal dependency, the resources are shared in no particular sequential order and in a many-to-many type of dependency to increase collaborative advantage [16]. Oil and gas companies can share onshore and offshore facilities and logistics infrastructure. The extent of dependency can vary across different countries and practices are not consistent throughout the globe. Furthermore, these companies are familiar with linked and complex technologies for information sharing. Thus the interorganizational dependency of the oil and gas companies is sequential or reciprocal varying across different continents throughout the world. When discussing the levels of digitization in companies in the oil and gas industry as a whole, we need to consider upstream and downstream operations separately. Due to narrower profit margins and direct relation with end customers, downstream oil and gas companies have started using digitization strategies earlier than the upstream companies. The past, present and potential future of digitization in oil and gas are summarized in Table 2. 
Table2. Developments in digitization for upstream and downstream companies (Based on [2])

\begin{tabular}{lll}
\hline & Upstream & Downstream \\
\hline Past & $\begin{array}{l}\text { Information technology has } \\
\text { traditionally not been seen as an } \\
\text { essential element of operations. }\end{array}$ & $\begin{array}{l}\text { Sensors available but information } \\
\text { stored in discrete units }\end{array}$ \\
$\begin{array}{l}\text { Developing powerful new capabilities } \\
\text { to benefit from smarter exploration, } \\
\text { easier capture, safer operations and } \\
\text { much better utilized labor }\end{array}$ & $\begin{array}{l}\text { Embedded smart sensors in vessels, } \\
\text { tanks, compressors, and turbines send } \\
\text { real-time data to control rooms in } \\
\text { which a handful of experts can } \\
\text { monitor processes and provide } \\
\text { diagnostics } \\
\text { Future }\end{array}$ \\
& $\begin{array}{l}\text { Connecting biometric data to improve } \\
\text { operator safety and in enabling } \\
\text { intelligent materials movement within } \\
\text { facilities }\end{array}$ \\
\hline
\end{tabular}

\section{Supply Chain Visibility in the Oil and Gas Industry}

The aim of digitization projects is ultimately to improve supply chain visibility. Oil and gas companies need to set the goal as virtualization of a supply chain with the following attributes [15]:

- Complete horizontal integration in which data from feedstock to product trading are integrated

- Achieving strategic fit through convergence in strategy, planning and scheduling

- Modularity to enable flexibility in implementation stage

- Scalability so that the applications are suitable for the most simple or complex supply chains

- Interactivity for collecting effective customer feedback

- Real time optimization speed with direct links to online plant optimization

Supply chain visibility increases if the company has more control on its supply chain. Fully integrated companies have better control over their supply chains and access to customer feedback [11]. This feedback in turn can influence the quality of their upstream processes. The major Norwegian oil company, Statoil, considered outsourcing five processes: routing of supply vessels, daily coordination of the flow of supplies, performance evaluation of suppliers and logistics providers, problem solving and conflict negotiation and influencing and improving the supply chain [4]. They used transactional cost analysis to understand the effects of outsourcing each of these processes and found that only outsourcing the routing of supply vessels generate a substantial advantage. Although by outsourcing the company can concentrate on its core competencies, it stood to lose visibility into transaction-specific data as well as control over its supply chain. 
Supply chain visibility is closely linked with the agility and competitiveness of companies. Lean processes create agility and companies need to reduce waste in their operations to be lean [3]. Agile companies outperform others and thus gain competitive advantage.

Companies in the oil and gas industry employ various software systems for managing their supply chains. However, most solution providers focus only on supply chain management (SCM) or enterprise resource planning (ERP) solutions. Thus, substantial effort may be needed to integrate disparate SCM and ERP solutions. Furthermore, only a few of the SCM software packages incorporate real-time vehicle routing and scheduling (VRS) capabilities. To develop a real-time end-to-end, digital ecosystem, oil and gas companies need to be able to achieve better integration between their software platforms. The current capabilities of the major software packages in the ERP, SCM and VRS space are shown in Fig1 (based on [22],[23 and [24]).

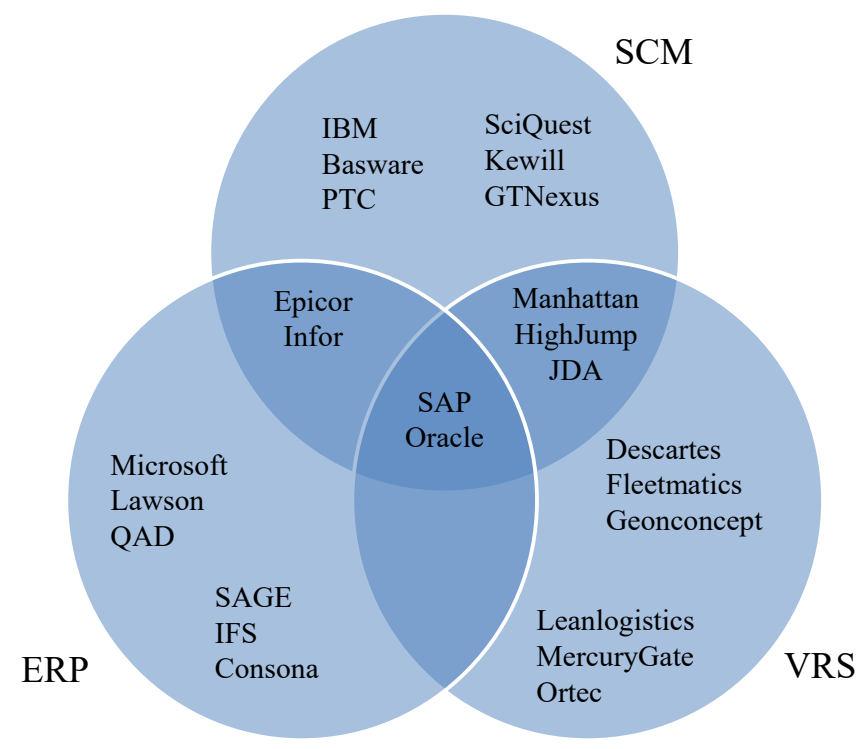

Fig1. Capabilities of major software companies in terms of SCM, ERP and VRS (Based on [22], [23] and [24])

SAP and Oracle are the only two major software vendors which provide all three types of solutions. The choice of solution would depend on different cost and performance considerations for oil and gas companies. When companies choose to use more than one software system, the efficiency of data transfer between the systems becomes vitally important. This necessitates the design of an efficient data integration architecture. Companies need to be able to address problems caused by interruptions in data transfer between the software solutions as well as potential corruptions in the data. The planning and execution processes for a company using multiple software solutions are depicted in Fig 2. The SCM software requires relevant master and transactional data to generate a plan. This data is stored in ERP system 
and transferred to SCM system. The SCM software generates a plan after forecasting and optimizing the supply chain drivers. The execution plan generated by the SCM software is then transferred to the ERP system as an order generation, followed by real-time execution and reconciliation. While these processes are running new data is obtained from other data sources like digital data sources and manual entries. The new data is transferred in a batch process to the SCM software to generate the next execution plan. Since the SCM software works discretely and ERP works continuously there is always a gap between the plan and the real-time execution and thus moving the company away from the goal of achieving a fully integrated digital ecosystem. Thus, although it may seem to be cheaper to use multiple software packages at first sight, companies also need to consider the efficiencies that could be gained in a fully integrated digital ecosystem.

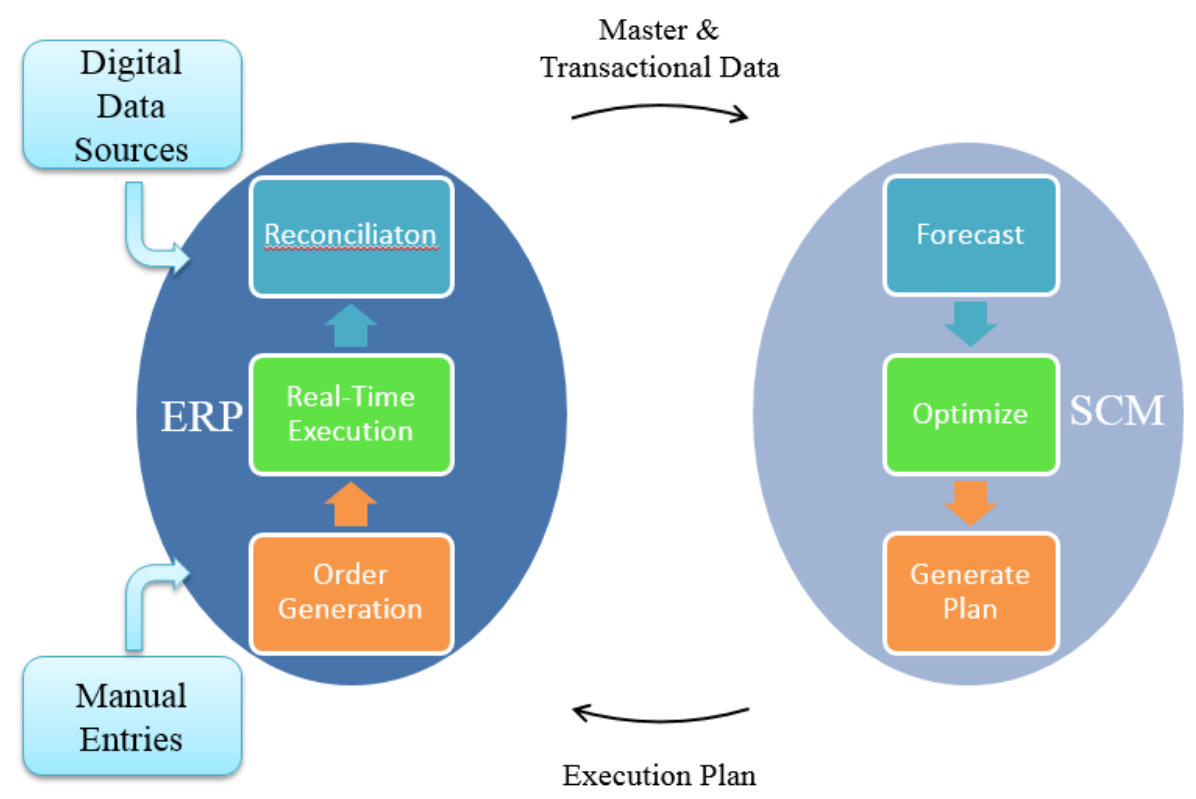

Fig2. Planning and execution processes for companies using multiple software solutions

\section{Discussions}

Digitization forms the backbone for supply chain visibility improvement efforts. As a company invests more in digitization, it starts to get greater insight from its operations. When the company extends its visibility through all operations and removes wasteful information, it starts to become more agile and thus it gains greater ability to respond to the variations in its operations. Supply chain agility and responsiveness are affected by the achievable extent of visibility. In latecomer 
industries such as oil and gas these changes have been gradual. However, the evolution towards digital ecosystems requires greater intensiveness in digitization efforts among all key players in the supply chain. Fig 3 summarizes these stages in digital evolution. Stage 1 involves digitization efforts and resultant visibility. Stage 2 involves the achievement of agility and responsiveness. Stage 1 and Stage 2 do not represent single instances in time as digitization efforts continue over the period of years and have changing influence on Stage 2. Stage 3 involves a final stage of evolution into a digital ecosystem through the contributions and collaboration of all relevant players in the supply chain.

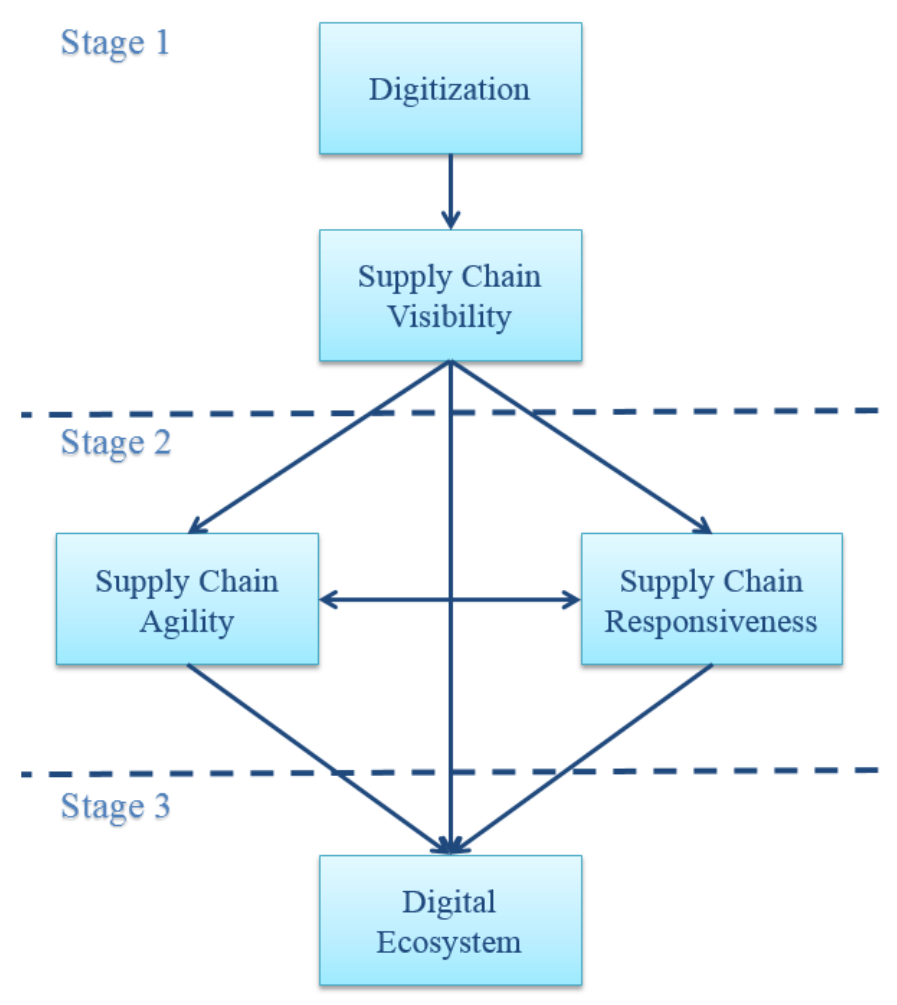

Fig. 3. Supply chain evolution toward digital ecosystem for oil and gas industry

The first author's industry experience and the previous business and academic literature suggest that the oil and gas industry has begun major digitization initiatives. These efforts are far more advanced in the downstream context. 


\section{Conclusions}

Oil and gas companies have understood the importance of digitization and are improving their supply chains by employing digital strategies, using smart manufacturing, designing digital business models and using data analytics as core competencies. A majority of these companies are only at the first stage of the evolution toward a digital ecosystem and are working on their visibility improvement efforts. These companies need to augment their efficiency in exchanging information, increase transparency and remove the friction in their information flow. The development of flexible digital ecosystems involves companies which employ virtualized processes, virtualized customer interfaces, and collaborate with other firms in the industry. However, there is no one-size-fits-all solution for oil and gas supply chains across the world with the increasing speed of digitization and the nature of technologies adopted. Academic researchers have a role to play here in observing and analyzing current efforts, participating in the development of innovative solutions and informing industry of successes, failures and contextual drivers.

\section{References}

1. Kohli, R., Johnson, S.: Digital Transformation In Latecomer Industries: CIO and CEO Leadership Lessons From Encana Oil \& Gas (USA) Inc. MIS Quarterly Executive 10, $141-157(2011)$

2. Strategy\&, http://www.strategyand.pwc.com/reports/industry4.0

3. Yusuf, Y.Y., Gunasekaran, A., Musa, A., Dauda, M., El-Berishy, N.M., Cang, S.: A Relational Study of Supply Chain Agility, Competitiveness and Business Performance in the Oil and Gas Industry. International Journal of Production Economics 147, 531 - 543 (2014)

4. Aas, B., Buvik, A., Cakic, D.: Outsourcing of Logistics Activities in a Complex Supply Chain: A Case Study from the Norwegian Oil and Gas Industry. International Journal of Procurement Management, 1, 280-296 (2008)

5. Tapping The Power of Big Data for the Oil and Gas Industry, IBM Company (2013)

6. Hamzeh, H.: Application of Big Data in Petroleum Industry (2016)

7. Forbes Logistics and Transportation, https://www.forbes.com/sites/kevinomarah/2016/11/17/digitization-in-supply-chain-fivekey-trends/

8. Baaziz, A., Quoniam, L.: How to Use Big Data Technologies to Optimize Operations in Upstream Petroleum Industry. International Journal of Innovation 1, 19-25 (2013)

9. Henriette, E., Feki, M., Boughzala I.: The Shape of Digital Transformation: A Systematic Literature Review. MCIS 2015 Proceedings 10, 1-13 (2015)

10. Trkman, P., Stemberger, M., Jakli, J., Groznik, A., Indihar, M., Temberger, S.: Process Approach to Supply Chain Integration. Supply Chain Management: An International Journal 12, 116-128 (2007)

11. Chima, C., Hills, D.: Supply-Chain Management Issues in the Oil and Gas Industry. Journal of Business \& Economics Research (JBER) 5, 27-36 (2011)

12. Katz, R, Koutroumpis, P., Callorda F.M.: Using a Digitization Index to Measure the Economic and Social Impact of Digital Agendas. Info 16, 32- 44 (2014) 
13. Xue, L., Zhang, C., Ling, H., Zhao, X.: Risk Mitigation in Supply Chain Digitization: System Modularity and Information Technology Governance. Journal of Management Information Systems, 30:1, 325-352 (2013)

14. Francis, V.: Supply Chain Visibility: Lost In Translation?. Supply Chain Management: An International Journal 13,180-184 (2008)

15. Lasschuit, W., Thijssen, N.: Supporting Supply Chain Planning and Scheduling Decisions in the Oil and Chemical Industry. Computers and Chemical Engineering 28, 863-870 (2004)

16. Kumar, K., Van Dissel, H.G.: Sustainable Collaboration: Managing Conflict and Cooperation in Interorganizational Systems. MIS Quarterly 20, 279-300 (1996)

17. Prater, E., Biehl, M., Smith, M. A.: International Supply Chain Agility - Tradeoffs between Flexibility and Uncertainty. International Journal of Operations \& Production Management 21, 823-839 (2001)

18. Gunasekaran, A., Lai, K.H., Cheng, T.C.E: Responsive Supply Chain: A Competitive Strategy in a Networked Economy. Omega 36, 549-564 (2008)

19. ATKearney, http://www.atkearney.com.au/documents/10192/6500433/Digital+Supply+Chains.pdf/

20. Gartner, http://www.gartner.com/technology/topics/digital-ecosystems.jsp

21. Cao, M., Zhang, Q.: Supply Chain Collaboration: Impact on Collaborative Advantage and Firm Performance. Journal of Operations Management 29, 163--180 (2011)

22. Modern Materials Handling, http://www.mmh.com/article/top_20_software_suppliers

23. Enterprise Innovation,

https://www.enterpriseinnovation.net/files/whitepapers/top_10_erp_vendors.pdf

24. Gartner, https://www.gartner.com/doc/3452617/market-guide-vehicle-routing-scheduling 